\title{
MAPEAMENTO GEOMORFOLÓGICO NA ESCALA 1:50.000 DO BAIXO CURSO DA BACIA DO RIO MURIAÉ NO ESTADO DO RIO DE JANEIRO
}

\author{
Cristiane Chapeta Mattoso Franco ${ }^{(a)}$ \\ ${ }^{\text {(a) Departamento de Geografia/Universidade Federal Fluminense, cristianechapeta@ gmail.com }}$
}

\section{EIXO: BACIAS HIDROGRÁFICAS E RECURSOS HÍDRICOS: ANÁLISE, PLANEJAMENTO E GESTÃO}

\begin{abstract}
Resumo
O relevo, por ser um elemento tão dinâmico e diverso em sua gênese, formas e composições, torna mais complexa e difícil a tarefa de representar tal elemento em um plano, como um mapa. No entanto, com o avanço tecnológico e das técnicas de sensoriamento remoto está se tornando cada vez mais possível obter dados e informações precisas sobre a superfície terrestre e assim evoluir, não só o conhecimento da ciência geomorfológica, como também, de ações para planejamento e gestão de determinadas áreas. A elaboração mapa geomorfológico, objetivo deste trabalho, busca auxiliar na melhor compreensão das características e história evolutiva do relevo que se encontra na área de estudo. E para isso, utiliza-se do saber geomorfológico e seus conceitos a fim de analisar os elementos presentes na superfície em questão, assim como os elementos e processos que atuam ou já atuaram na sua evolução.
\end{abstract}

Palavras-chave: relevo, mapeamento geomorfológico, bacias hidrográficas.

\section{INTRODUÇÃO}

O mapeamento geomorfológico busca representar em um plano, a distribuição espacial das formas e compartimentos do relevo, em parte ou na sua totalidade, a depender da escala utilizada, a fim de auxiliar no estudo e análise dos mesmos. O reconhecimento do relevo com o uso de geotecnologias vem se tornando uma prática recorrente e de grande importância, uma vez que, a depender de suas características, o relevo se apresenta como obstáculo para a ocupação humana, ou a favorece. A análise e conhecimento de suas formas, gênese e processos atuantes auxilia tanto academicamente quanto em questões práticas, como planejamento e gestão do espaço urbano e/ou rural e questões ambientais, pois permite orientar a ocupação e uso do solo, prever e minimizar danos aos seres que o ocupam e ao ambiente.

Pelo fato de o relevo ser geralmente bem destacado em imagens de satélite, bem como pela disponibilidade de dados multitemporais que possibilitam o estudo de processos morfodinâmicos, a ciência geomorfológica é fortemente beneficiada pela tecnologia de sensoriamento remoto (FLORENZANO, 2008). Para auxiliar na elaboração das cartas geomorfológicas, as novas tecnologias de geoprocessamento, trazem maior precisão e fidelidade para os dados espaciais tornando possível uma maior precisão na interpretação das formas de relevo. Estas que apresentam caráter 
XVII Simpósio Brasileiro de Geografia Fisica Aplicada

I Congresso Nacional de Geografia Física

\section{OS DESAFIOS DA GEOGRAFIA FÍSICA NA FRONTEIRA DO CONHECIMENTO \\ Instituto de Geociências - Unicamp \\ Campinas - SP \\ 28 de Junho à 02 de Julho de 2017}

individual, local, como uma colina, uma planície ou uma escarpa podem, em conjunto com outras formas semelhantes, comporem um compartimento a fim de caracterizar grandes regiões, com certo grau de generalização. A Cartografia Geomorfológica é capaz de espacializar estas formas do relevo e identificar suas estruturas, bem como suas dinâmicas e seus processos. Utilizar uma Bacia Hidrográfica como unidade de análise e planejamento se mostra ideal por se tratar de uma porção naturalmente limitada da superfície terrestre, onde suas formas de relevo características podem ser descritas e analisadas pelos termos da geomorfologia e ainda abrange variáveis climáticas básicas, sendo possível até mensurá-las. É também um sistema equilibrado em termos de entradas e saídas de fluxos de água, sedimentos e energia.

Elaborar o mapa geomorfológico do baixo curso da Bacia Hidrográfica do Rio Muriaé no estado do Rio de Janeiro, na escala de 1:50.000, visa ser um meio de auxílio ao planejamento e gestão da área de estudo, que acomoda perímetros urbanos, e sofre com inundações periódicas, resultando em prejuízos materiais e de vida.

\section{MATERIAL E MÉTODOS}

\section{1 Área de estudo}

A área de estudo corresponde ao baixo curso da Bacia do Rio Muriaé (Figura 1). Apresenta área de cerca de $1.500 \mathrm{~km}^{2}$, sendo que $520,28 \mathrm{~km}^{2}$ situadas na Região Noroeste Fluminense (35\% da área de estudo) e $979,72 \mathrm{~km}^{2}$ (65\% da área de estudo) pertencentes a Região Norte Fluminense

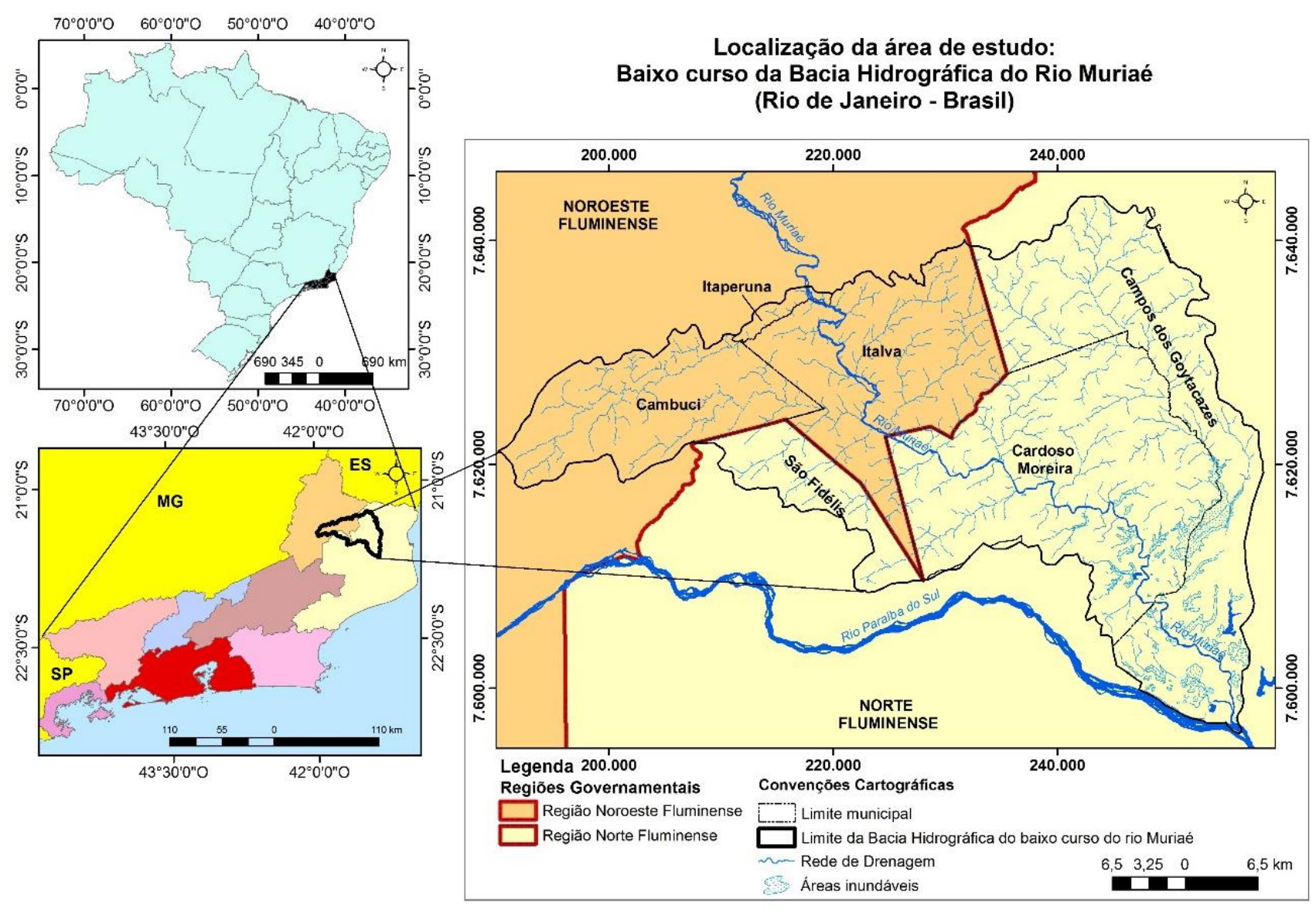


XVII Simpósio Brasileiro

de Geografia Fisica Aplicada

I Congresso Nacional

de Geografia Física

\section{OS DESAFIOS DA GEOGRAFIA FÍSICA NA FRONTEIRA DO CONHECIMENTO \\ Instituto de Geociências - Unicamp \\ Campinas - SP \\ 28 de Junho à 02 de Julho de 2017}

(AMORIM, REIS e FERREIRA, 2016).

O Rio Muriaé lança suas águas no Rio Paraíba do Sul no município de Campos dos Goytacazes (PRADO et al., 2005). A Bacia Hidrográfica do Rio Muriaé é dividida em três compartimentos: Alto curso (situado no Estado de Minas Gerais), médio curso (municípios da Região Noroeste Fluminense) e o baixo curso, que se situa no Estado do Rio de Janeiro

\subsection{Procedimentos metodológicos}

Para atender aos objetivos propostos deste trabalho, a primeira etapa foi a realização de uma revisão bibliográfica sobre a cartografia do relevo enfatizando o mapeamento geomorfológico, além de dados referentes aos aspectos físico-naturais da área em estudo. A escala de 1:50.000 adotada neste projeto, sendo escala intermediária, atende à representação dos conjuntos de formas de relevo que se distribuem na área mapeada. Tais formas, como foi observado durante o estudo realizado, se diferem entre as derivadas dos processos de dissecação, e dos processos de acumulação.

Definida a escala taxionômica de trabalho, foi proposta uma adaptação da metodologia exposta por Silva e Rodrigues (2009), que extraem os dados morfométricos a partir das imagens geradas através das imagens SRTM trabalhadas estatisticamente no projeto Topodata, coordenado por Valeriano (2005). O primeiro passo foi fazer o download de todos os arquivos SRTM correspondentes a área de estudo. De posse da base de dados, agrupou-se em um único arquivo no formato raster, e com o uso do módulo Spatial Analyst Tools, ferramenta Extração por máscara, obteve-se apenas uma única imagem da área de estudo. A partir desta imagem e com o auxílio do software ArcGIS 10.3 foi possível elaborar os produtos cartográficos de hipsometria (a fim de identificar as áreas com maior desnível altimétrico, e as áreas de topos e nascentes), declividade, relevo sombreado e geológico da área de estudo. A partir da correlação entre estes produtos, além da interpretação das espacialidades entre as curvas de nível e a elaboração de perfis, pôde-se fazer análises morfométricas que auxiliaram na definição das formas de relevo. Os dados geológicos deram suporte na delimitação dos domínios morfoestruturais, e foram também correlacionados os padrões de idade e o tipo de litologia obtidos a partir dos mapas geológicos.

A organização do mapa geomorfológico foi elaborada com o uso do software ArcGIS 10.3, seguindo os seguintes passos:

- Delimitação das Unidades Morfoestruturais: a partir do mapa geológico da área em estudo, agrupou-se por período de gênese das unidades geológicas e por características da litologia os diferentes domínios morfoestruturais. Foi criado para cada uma das unidades morfoestruturais, um arquivo shapefile individualizado, que na área em estudo deram origem 
XVII Simpósio Brasileiro

de Geografia Fisica Aplicada

I Congresso Nacional

de Geografia Física
OS DESAFIOS DA GEOGRAFIA FÍSICA NA FRONTEIRA DO CONHECIMENTO

Instituto de Geociências - Unicamp

Campinas - SP

28 de Junho à 02 de Julho de 2017

a três arquivos: Depósitos Sedimentares Quaternários, Depósitos Sedimentares Terciários e o Cinturão Orogênico do Atlântico.

- Separação por Unidades Morfoestruturais a Imagem Classificada, a Imagem SRTM e a Imagem Sombreada: este procedimento foi adotado para facilitar a interpretação dos dados morfométricos por Domínio Morfoestrutural. Para tal foi necessário gerar um arquivo para cada domínio morfoestrutural. Depois, selecionou-se o arquivo ao modelo digital de terreno, e extraiu-se as informações referentes à altimetria, ao relevo sombreado, a reclassificação do MDE e à declividade para cada Domínio Morfoestrutural.

Já com as imagens individualizadas de cada morfoestrutura, partiu-se para a identificação dos Compartimentos de Relevo, para tanto, foi necessário sobrepor as curvas de nível à imagem sombreada, e assim, identificando as diferenciações de sombra e rugosidade e associando-as com as curvas de nível que possam limitar essas diferenciações. Outra forma de identificação dos compartimentos de relevo foi com o auxílio de perfis topográficos, importantes por representar um corte transversal da superfície demonstrando os diferentes padrões altimétricos ao cortar várias unidades de relevo. Deste modo, com as classes definidas, foi necessário fazer uma reclassificação supervisionada a partir da imagem classificada. O próximo passo foi transformar essa imagem Raster em shapefile para que fosse possível editar os polígonos e acrescentar informações a eles.

Para editar os polígonos lhes conferindo informações distintas foi necessário, primeiramente, inserir uma nova coluna na tabela de atributos do shapefile em questão. Anteriormente ao início da edição, deve-se possuir esquematizada, a nomenclatura dos diferentes compartimentos de relevo. Essa classificação levou em consideração os atributos morfométricos, relacionados aos valores topográficos, e os atributos morfológicos, relacionados à geometria/tipologia das formas. As formas semelhantes foram identificadas a partir da interação entre Morfoestrutura x Compartimentos e o formato das curvas de nível e interpretação do relevo sombreado. Para confirmar as feições predominantes, realizou-se a interpretação visual de imagens de satélite RapidEye, do ano de 2014 no software ArcGIS 10.3, adquiridas pelo Ministério do Meio Ambiente (MMA) e cedidas para o uso neste estudo.

\section{RESULTADOS E DISCUSSÕES}

Ao fim da elaboração do mapa geomorfológico do baixo curso da bacia do rio Muriaé (Figura 2), foram descritas três classes distintas de Domínios Morfoestruturais, cada qual relacionada com seu respectivo Domínio Morfoescultural, destacando também as formas de relevo predominantes na área mapeada. Afim de facilitar a discussão dos processos relacionados a gênese e evolução das formas de relevo da área de estudo, este trabalho propõe a sua análise a partir dos processos 
morfogenéticos atuantes: as formas derivadas do processo de dissecação e as formas originadas dos processos de acumulação. 
XVII Simpósio Brasileiro de Geografia Fisica Aplicada

I Congresso Nacional de Geografia Física

\section{OS DESAFIOS DA GEOGRAFIA FíSICA NA FRONTEIRA DO CONHECIMENTO}

Instituto de Geociências - Unicamp

Campinas - SP

28 de Junho à 02 de Julho de 2017

\section{MAPA GEOMORFOLÓGICO DO BAIXO CURSO DO RIO MURIAÉ-RJ}

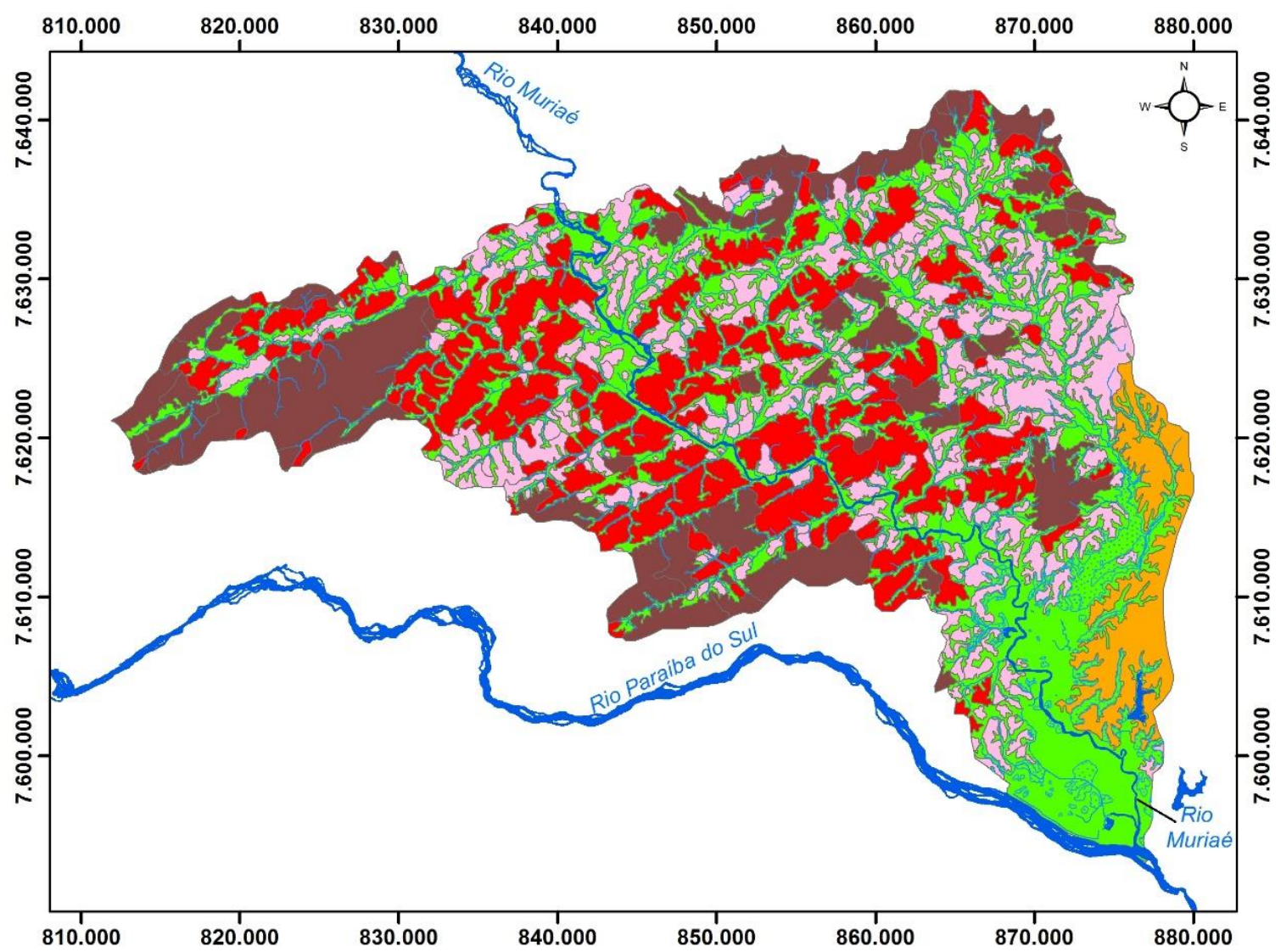

LEGENDA

\begin{tabular}{|c|c|c|}
\hline $\begin{array}{c}\text { Domínios } \\
\text { Morfoestruturais }\end{array}$ & $\begin{array}{c}\text { Domínios } \\
\text { Morfoesculturais }\end{array}$ & Formas de relevo predominantes \\
\hline $\begin{array}{c}\text { Depósitos Sedimentares } \\
\text { Quarternários }\end{array}$ & Formas de acumulação & Planicies Fluviais \\
\hline $\begin{array}{c}\text { Depósitos Sedimentares } \\
\text { Terciários }\end{array}$ & $\begin{array}{c}\text { Formas de dissecação em } \\
\text { depósitos sedimentares }\end{array}$ & \\
\hline Cobuleiros \\
Cinturão Orogênico \\
do Atlântico
\end{tabular}

\section{Convenções Cartográficas}

$\sim \sim$ Rede de Drenagem

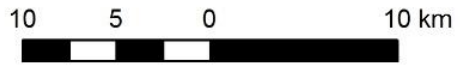

Figura 2: Mapa Geomorfológico do Baixo Curso da Bacia Hidrográfica do rio Muriaé

\subsection{Formas de relevo derivadas do processo de dissecação}


XVII Simpósio Brasileiro

de Geografia Fisica Aplicada

I Congresso Nacional

de Geografia Física

\section{OS DESAFIOS DA GEOGRAFIA FÍSICA NA FRONTEIRA DO CONHECIMENTO \\ Instituto de Geociências - Unicamp \\ Campinas - SP \\ 28 de Junho à 02 de Julho de 2017}

As formas de relevo derivadas do processo de dissecação são comuns em áreas em que a ação fluvial é atuante na individualização de formas. Os rios são responsáveis pelos processos de entalhamento dos vales, a partir do processo de denudação.

Foi observado através do Mapa Geológico da área de estudo (Figura 3) que as rochas datadas do período Pré-cambriano e do período Terciário foram ao longo do tempo geológico dissecadas pela ação fluvial individualizando formas relacionadas as Escarpas, Morros, Colinas e Tabuleiros (Figura 2).

Almeida et al. (1976) e Heilbron et al. (1995) apud CPRM (2000) dizem que o Cinturão Orogênico do Atlântico representa uma das significativas feições geotectônicas da fachada atlântica brasileira, que se estende do estado de Santa Catarina até o norte da Bahia. É composto por diversas faixas de dobramento, que podem ser identificadas em todo o estado do Rio de Janeiro. Esse cinturão constitui-se em um conjunto diverso de rochas graníticas e gnáissicas, submetidas a diversos eventos orogenéticos ao longo do Pré-Cambriano. Para caracterizar geologicamente o Cinturão Orogênico do Atlântico, organizou-se com base no mapeamento geológico realizado pelo DRM-RJ, as Unidades Geológicas a partir da sua gênese e evento geotectônico responsável por sua formação.

MAPA DE UNIDADES GEOLÓGICAS DO BAIXO CURSO DA BACIA HIDROGRÁFICA DO RIO MURIAÉ-RJ

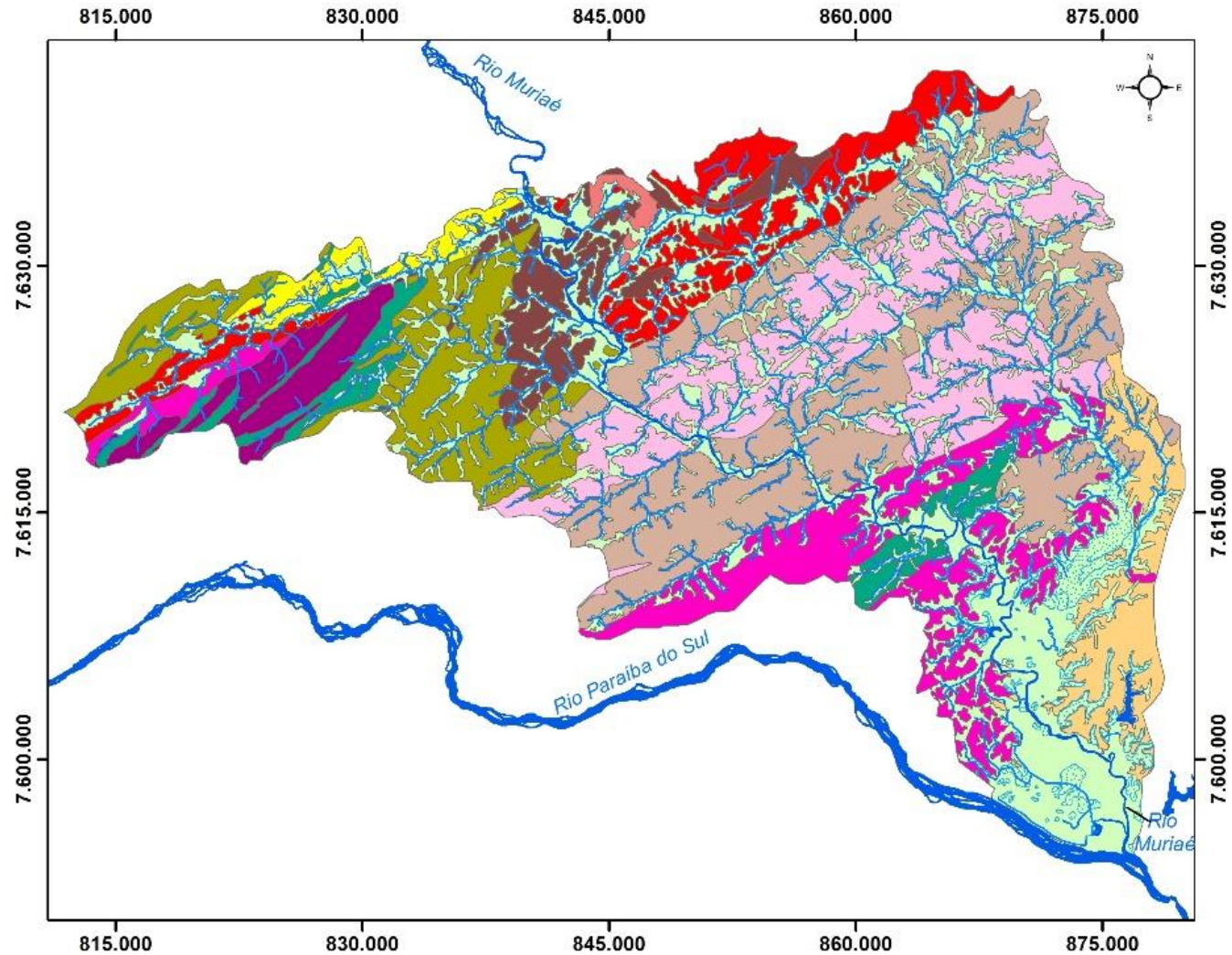

\section{Legenda}

Unidades Geológicas

Quaternário

$\square$ Qa - Sedimentos Fluviais

Terciário

Tb - Formacao Barreiras

Neoproterozóico/Cambriano

$\square$ pCllag - Unidade Angelim

pClbj - Unidade Bela Joana

pClmv - Unidade Monte Verde

pCllse - Unidade Santo Eduardo

pCllljp - Unidade São Joao do Paraiso

$\square$ pCllsv - Unidade Serra Vermelha

pCIllva - Unidade Vista Alegre

Neoproterozóico

pClcl - Unidade Catalunha

Mesoproterozóico

pClltv - Unidade Italva

pCllsj - Unidade Sao Joaquim

pCllsf - Unidade Sao Fidelis

Convenções Cartográficas

$\sim$ Rede de Drenagem

Figura 3: Mapa Geológico do baixo curso da Bacia Hidrográfica do Rio Muriaé

Fonte: DRM (1978-83)

Organização: Cristiane Chapeta Mattoso Franco 
Segundo dados da CPRM (2000), as unidades geológicas de Italva e São Joaquim foram agrupadas no projeto por serem semelhantes, e datam das Eras Meso/Neoproterozóico, a principal característica apontada é a presença de mármores. A unidade São Fidélis, também datada das Eras Meso/Neoproterozóico, representa parte significativa da área de estudo mapeada, diferencia-se pela presença de "“paleomigmatitos’ heterogêneos (dominantes) e homogêneos (...). Apresentam-se com intercalações de faixas cinza-claras que exibem um bandeamento gnáissico bem definido, milimétrico a centimétrico, faixas esbranquiçadas (...) e intercalações quartzosas" (AMORIM, 2014, p. 32).

Já a unidade Serra Vermelha, tem sua gênese entre Neoproterozóico/Cambriano, sendo caracterizada pela existência de rochas expostas presentes nas áreas da Serra Vermelha e Serra das Águas Quentes. Nesta unidade podem ser encontrados mármores e gnaisses (CPRM, 2000). A unidade Catalunha, por sua vez, datada do Neoproterozóico/Cambriano, apresenta metamorfitos e migmatitos foliados, com recorrente presença de óxidos de ferro e manganês. Destaca-se ainda a presença de corpos de mármore dolomíticos, comumente sob a forma de lentes alongadas. A unidade Santo Eduardo de origem do Neoproterozóico/Cambriano, é composta por "paleo-migmatitos" heterogêneos, apresentando domínios homogêneos, porfiroblásticos e domínios gnáissicos bandados. Faixas leptiníticas de espessura variável são recorrentes, tal qual intercalações de rochas calcossilicatadas, de anfibólio, de quartizitos e corpos de mármore (CPRM, 2000).

A unidade Bela Joana também formada durante o Neoproterozóico/Cambriano, é composta essencialmente por rochas maciças e homogêneas, granulação média a grosseira, apresentando ainda algumas variações para os tipos gnáissicos. Por fim, encontra-se na unidade Angelim, originada no Neoproterozóico/Cambriano, rochas micro, meso e macroscopicamente homogêneas, de estrutura maciça ou fracamente orientada, textura porfiroblástica e semiporfiroblástica. A coloração do material varia entre cinza claro, médio ou escuro, de acordo com o menor ou maior teor de máficos.

Este conjunto de diferentes rochas, com resistências diferenciadas aos processos erosivos e de denudação deram origem a formas de relevo na área em estudo: as escarpas serranas, os morros e as colinas. A individualização dessas formas de relevo deu-se por conta da presença da rede de drenagem, principal agente de dissecação do relevo e responsável pela modelagem das estruturas atuais. É caracterizada como densa e não apresenta padrão específico de drenagem, uma vez que é condicionado pela estrutura litológica. Pode-se notar pelas Figuras 2 e 3 que nas margens dos rios formam-se depósitos quaternários decorrentes da ação fluvial, que neste trabalho denominamos de Depósitos Sedimentares Quaternários. É possível observar também que as rochas do Cinturão Orogênico do Atlântico fazem limite a sudeste com a Formação Barreiras, que forma os Depósitos Sedimentares Terciários. 
As escarpas serranas foram estabelecidas com altitude acima de 300 metros. A maior recorrência de serras pode ser observada nas margens oeste, sudoeste e nordeste do mapa geomorfológico, apresentando ainda algumas formas em contato com morros, colinas e planícies na porção mais central do mapa.

Caracterizaram-se como morros as formas que apresentam amplitude entre 100 e 200 metros. Essa forma de relevo é encontrada principalmente em contato com as planícies fluviais, onde se percebe certa concentração, e ainda em conjuntos mais isolados em diferentes porções da área mapeada. $\mathrm{Na}$ área em estudo, a presença dos morros circundados por colinas é decorrente da maior resistência ao desgaste do material pelos processos erosivos.

Finalmente, as colinas sendo formas residuais dos processos de dissecação, apresentam amplitude entre 20 e 100 metros. A intensa atuação dos processos meteóricos, principalmente relacionados ao clima tropical, com médias elevadas de precipitação e altas temperaturas formam espessos mantos de alteração, e por conta dos processos erosivos, tais feições são esculpidas de forma a reduzir cada vez mais a sua altura e diminuindo a sua declividade. As colinas estão presentes de maneira significativa, conforme representação do mapa geomorfológico (Figura 2) e apresenta-se em todas as unidades geológicas (Figura 3).

O Domínio Morfoestrutural denominado Depósitos Sedimentares Terciários, apresenta a Formação Barreiras que aflora na região do delta do rio Paraíba do Sul, nos municípios de Campos dos Goytacazes e São Francisco de Itabapoana (CPRM, 2000). A origem da Formação Barreiras está diretamente relacionada aos processos de Reativação Wealdeniana, responsáveis pelos processos distintivos que fragmentaram o continente Sul-Americano e o continente Africano, que originou diversas bacias sedimentares ao longo da Costa Atlântica, preenchidas por sedimentos de idade cretácea e terciária. No compartimento de relevo Tabuleiros Costeiros, distinguem-se formas de relevo distintas, de topo aplainado e de topo convexos. Diferente das áreas próximas ao litoral, à medida que se adentram a Formação Barreiras ao interior, sua cota altimétrica é superior a $20 \mathrm{~m}$, chegando a atingir 120 metros, apresentando elevada densidade de drenagem predominantemente nos padrões paralelo a dendrítico.

\subsection{Formas de acumulação}

Na bacia hidrográfica do rio Paraíba do Sul o Domínio Morfoestrutural Depósitos Sedimentares Quaternários tem sua origem em eventos associados a série de ambientes de sedimentação quaternária. Tais eventos estão relacionados a processos de acumulação decorrentes tanto a gênese continental e também transicional/marinho. No baixo curso do rio Muriaé esses processos deposicionais fazem 
limite, na porção continental, com rochas do embasamento de diferentes litologias e idades, e também a depósitos da Formação Barreiras.

Destaca-se que as planícies fluviais no baixo curso do rio Muriaé margeiam os canais fluviais, mas que na proximidade com a sua confluência com o rio Paraíba do Sul, esta área por conta da baixa cota altimétrica e baixa declividade configura-se uma planície de inundação. Essas formações coincidem com as áreas com declividade inferior a $2 \%$ e vales encaixados sujeitos às inundações periódicas. A principal característica dessas formas de acumulação é a presença de terrenos mal drenados, associados a acúmulo de materiais argilo-arenosos fluviais e alúvio-coluviais.

Reis e Amorim (2014) destacam a recorrência dos fenômenos de inundações no baixo curso do rio Muriaé, principalmente nos municípios de Cardoso Moreira, Italva e Itaperuna. Os autores afirmam que o fenômeno ocorre durante o período mais úmido, entre os meses de novembro a março, e que, os episódios de inundações são agravados por conta da ocupação das margens dos rios tanto por áreas urbanas como por áreas rurais.

\section{CONSIDERAÇÕES FINAIS}

Cabe considerar que o tutorial elaborado por Silva e Rodrigues (2009) utilizado para aprendizagem e acompanhamento na elaboração do mapa geomorfológico do trabalho apresentado, foi adaptado para melhor atender os objetivos propostos. O mapa proposto pelo tutorial, por exemplo, tem escala menor, 1:250.000, enquanto o mapa geomorfológico do baixo curso da Bacia Hidrográfica do rio Muriaé foi elaborado na escala 1:50.000. Assim como a versão do software utilizado no Tutorial de Cartografia Geomorfológica (ArcGIS9.2) é anterior a versão utilizada (ArcGIS10.3) para a elaboração do mapa geomorfológico deste trabalho, desse modo, foi necessária a consulta e pesquisa acerca das ferramentas do software que haviam sido atualizadas, renomeadas e/ou relocalizadas.

Os dados geológicos, tal qual o mapa de relevo sombreado e da rede de drenagem presente na área de estudo, permitiram observar pouco controle estrutural da litologia em relação aos canais da bacia, sendo predominante o padrão de drenagem dendrítico.

A partir do mapa geomorfológico do baixo curso da bacia do rio Muriaé elaborado e dos resultados obtidos, em conjunto com os conceitos e processos apresentados que dizem respeito a gênese e modelagem do relevo, pode ser compreendido que a área mapeada possui formações antigas que remetem a diferentes Eras geológicas, tendo presenciado também diferentes climas. Tais formações, no entanto, são atingidas atualmente por fortes processos de dissecação, entre eles, a incisão dos canais da rede de drenagem presente na área, como também processos de acumulação, através das inundações periódicas dos canais que depositam sedimentos originários da intemperização de outras formas. Fica evidente, portanto, que o relevo estudado se encontra em condições 
morfoclimáticas que estão sendo responsáveis pelo desenvolvimento de uma nova configuração das suas formas, seja através do desgaste ou da deposição. Vale destacar que os processos aqui mencionados são, geralmente, lentos quando observados em escala histórica, mas de grande importância na compreensão do funcionamento do relevo a fim de melhor planejar futuros usos e ocupações de determinados espaços.

\section{BIBLIOGRAFIA}

AMORIM, R.; Reis, C.; Ferreira, C. Mapeamento dos Geossistemas e dos Sistemas Antrópicos como Subsídios de Áreas com Riscos a Inundações e Alagamentos no Baixo Curso da Bacia Hidrográfica do rio Muriaé (Rio de Janeiro - Brasil). Territorium (Coimbra), 2017.

CPRM, Companhia Brasileira de Recursos Minerais. Projeto Rio de Janeiro. Brasília: Serviço Geológico do Brasil, 2000, v. 1-8

FLORENZANO, T.G. Geomorfologia: conceitos e tecnologias atuais. São Paulo: Oficina de Textos, 2008

PRADO, R.B.; DANTAS, M.E; FIDALGO, E.C.C.; GONÇALVES, A.O.; SILVEIRA, M.M.L.; GUIMARÃES, P.V.; FERRAZ, R.P.D.; MANSUR, K.L., DOURADO, H.V.F. Diagnóstico do meio físico da Bacia Hidrográfica do rio Muriaé. Rio de Janeiro, EMBRAPA, 2005

REIS, C. H; AMORIM, R. R. Uso de sensores remotos com diferentes resoluções espectrais para a caracterização do uso e ocupação das terras de áreas com risco à inundação dos municípios de Italva e Cardoso Moreira, Rio de Janeiro, Brasil. In: RISCOS - Associação Portuguesa de Riscos, Prevenção e Segurança. (org.). Multidimensão e Territórios de Risco. 1ed.Coimbra: Imprensa da Universidade de Coimbra, 2014, v. 1, 2014. p. 123-128.

SILVA, T. I.; RODRIGUES, S. C. Tutorial de Cartografia Geomorfológica. Revista Geográfica Acadêmica. Volume 3, Número 2 - Dezembro 2009. 64p.

\section{AGRADECIMENTOS}

Ao financiamento concedido pela Fundação de Amparo à Pesquisa do Estado de São Paulo (FAPESP)

- Processo $n^{\circ} .2016 / 00007-3$. 